\title{
Assessment of Genetic Diversity in Indigenous Sesame Genotypes
}

\author{
Labhya Rani Gogoi ${ }^{1 *}$, Sushil Kumar Singh ${ }^{2}$ and R. N. Sarma ${ }^{1}$ \\ ${ }^{1}$ Department of Plant Breeding and Genetics, Assam Agricultural University, \\ Jorhat-785013, India \\ ${ }^{2}$ Department of Agricultural Biotechnology, Assam Agricultural University, \\ Jorhat-785013, India \\ *Corresponding author
}

\section{A B S T R A C T}

\section{Keywords}

D2 statistic, Genetic

diversity, Polymorphism,

Sesame, Simple sequence

repeats (SSR) markers

Article Info

Accepted:

17 May 2018

Available Online:

10 June 2018

Thirty-three indigenous genotypes of sesame (Sesamum indicum L.) were evaluated to assess the extent of genetic diversity based on phenotypic and marker-based genotypic data. Multivariate analysis revealed considerable genetic diversity in the material and led to their grouping into 8 clusters. The yield per plant contributed most to genetic divergence followed by days to $50 \%$ flowering and 1000 grain weight, respectively. Altogether, 78 alleles were detected with 27 polymorphic SSR markers, of which 49 were polymorphic $(62.82 \%)$ with an average of 2.89 alleles per locus. The polymorphism information content (PIC) value varied from 0.99 to 0.01 with a mean of 0.43 . Dendrogram analysis grouped the 33 genotypes into three separate clusters exhibiting a genetic similarity coefficient from 0.931 to 0.591 with an average of 0.754 . No relationship between geographic origin and genetic diversity was observed. Few genotypes were identified to be important for varietal improvement programme on the basis of their genetic distances and desirable cluster means. The result confirmed the presence of high genetic diversity among the local germplasm.

\section{Introduction}

Sesame (Sesamum indicum L.) is a diploid $(2 \mathrm{n}=2 \mathrm{x}=26)$ oilseed crops belong to family Pedaliacea. Sesame is basically a crop of the tropics and subtropics highly tolerate to drought because of its deep taproot system. Sesame has remarkable antioxidant function, rich in quality proteins and essential amino acids. The oil with $85 \%$ unsaturated fatty acids, is highly stable and has reducing effect on cholesterol and prevent coronary heart diseases. In spite of being a good source of healthy oil, it is not grown on a large extent due to very poor yield. India, Myanmar and China are the top three sesame producing countries in the world. India is the second largest producer with the productivity of 413 $\mathrm{kg} / \mathrm{ha}$ after China (1234 kg/ha) as compared to world's average of $535 \mathrm{~kg} / \mathrm{ha}$ (Anon. 2017). In Assam, during 2013-14 to 2015-16 area, production and productivity was 0.12 lakh ha, 0.90 lakh tones and $746 \mathrm{~kg} / \mathrm{ha}$ respectively (Anon., 2017). The low seed yield of sesame is a result of a lack in breeding attention (Ashri et al., 1989), and a lack of improved 
varieties for use by the farmers. Therefore serious efforts are necessary for developing high yielding varieties of good quality and high adaptive potential to the diverse climatic situations (Farooq et al., 2016).

India in general, and North Eastern India in specific is a rich source of biodiversity in Sesame (Bisht et al., 1998; Sharma et al., 2014). Traditional sesame landraces are an important source of genetic diversity for breeders and form the backbone of sesame breeding programme, which remains largely unexplored and uncharacterized. Morphological characteristics, being the important determinants of the agronomic value and taxonomic classification are widely used in assessing the genetic diversity. However, morphological markers have limitations in their ability to estimate genetic diversity because of strong influence from environmental factors, which make them highly dependent on the cultivation conditions. Molecular marker mediated diversity analysis is considered ideal due to its abundance, hyper-variability, multi-allelic and codominant nature (Sharma et al., 2009; Yepuri et al., 2013; Wu et al., 2014; Sehr et al., 2016). Since the studies on genetic diversity analysis combining morphological and molecular markers are limited in Indian sesame germplasm, the present study was carried out to compare the genetic diversity in sesame genotypes using morphological traits and SSR markers.

\section{Materials and Methods}

\section{Experimental materials and phenotyping}

A set of 33 genotypes (Table 1) collected from different parts of the North Eastern India were grown during Kharif, 2016 in a randomized block design with 3 replications. Out of these 33 genotypes, 22 genotypes were collected from different agro-climatic zone of Assam.
Seven genotypes were collected from Calcutta University, one from Arunachal Pradesh, one from Umium (Meghalaya) and rest two were HYV. Each genotype was sown in 3 rows of 4 $\mathrm{m}$ length with spacing of $30 \mathrm{X} 10 \mathrm{~cm}$ following recommended agronomic practices. Observations were recorded on height of first capsule bearing node $(\mathrm{cm})$, plant height $(\mathrm{cm})$, number of capsules per plant, number of branches per plant, capsule length $(\mathrm{cm})$, capsule width $(\mathrm{cm})$, number of seed per capsule, 1000 grain weight $(\mathrm{g})$, days to $50 \%$ flowering, days to maturity and yield per plant (g). Multivariate analysis was done as per Mahalanobis's $\mathrm{D}^{2}$ statistics described by Rao (1952) and the genotypes were grouped into different clusters following Tocher's method.

\section{DNA isolation}

The DNA was extracted from newly emerged fresh leave by modified CTAB method (Murray and Thompson, 1980). The modifications were made to improve the quality and quantity of the DNA. Isolation of genomic DNA from sesame is strenuous due to the presence of mucilage (viscous glue) which make it difficult to pipette out aqueous layers interferes at nucleic acid purification step. In this method $1 \mathrm{~g}$ of ground sesame leaves (using liquid nitrogen) were immediately transferred into extraction buffer solution consisting of $2.3 \mathrm{~g}$ Sorbitol, $1 \mathrm{~g} \mathrm{~N}$ laurylsorcosine, $0.8 \mathrm{~g}$ CTAB, $4.7 \mathrm{~g} \mathrm{NaCl}, 1 \mathrm{~g}$ PVP-40, 20mM EDTA(pH8), 10mMTris$\mathrm{HCl}(\mathrm{pH} 8), 20 \quad \mu \mathrm{l} \quad \beta$-marcaptoethanol, $1 \mathrm{ml}$ Triton X-100.Tubes containing the samples were then incubated for $10 \mathrm{~min}$ at $42^{\circ} \mathrm{C}$, then $30 \min 65^{\circ} \mathrm{C}$ in a water bath with gentle shaking and left to cool at room temperature for 5mins. Phenol: chloroform: Isoamyl alcohol mixture $(25: 24: 1)$ was added to each tube and centrifuge for 20 minutes at 12000 $\mathrm{rpm}$. After that final concentration of $6 \%$ PEG 600 was added to the aqueous phase and incubates for $30 \mathrm{mins}$ at room temperature. 
Then centrifuged for 20 minutes at 12,000 rpm. The cell debris was washed with $70 \%$ ethanol. The last drop of ethanol was removed by placing the tube face down on tissue paper. Finally isolated DNA was dissolved in TE buffer (10 mMTris, 1 mMEDTA, pH 8.0) and stored at $-20{ }^{\circ} \mathrm{C}$. The isolated genomic DNA was quantified on Nanodrop N.D.1000 system (V.3.3.0, Thermo Scientific, USA). And quality and integrity was further analysed using $0.8 \%$ agarose gel electrophoresis run with a power packset at $70 \mathrm{~V}$ for $1 \mathrm{~h}$ in $1 \mathrm{X}$ TAE buffer consisting of 0.04 MTris base, 17.4 M Glacial acetic acid, 0.001 M EDTA. DNA was subsequently diluted to finial concentration of $50 \mathrm{ng} / \mu \mathrm{l}$ for PCR based microsatellite analysis.

\section{PCR Amplification and gel analysis}

In total, 50 different SSR marker were used for PCR amplification (Table 2).The PCR was carried out in reaction volume $10 \mu \mathrm{l}$ volume containing $50 \mathrm{ng}$ template DNA, 1X PCR buffer, $0.2 \mathrm{mMdNTPs}, 0.5 \mathrm{pM}$ of each primer and $0.1 \mathrm{U}$ Taq polymerase (Takara). The PCR reaction conditions were an initial denaturation at $95^{\circ} \mathrm{C}$ for $5 \mathrm{~min}$, followed by 35 cycles of $95^{\circ} \mathrm{C}$ for $1 \mathrm{~min}$, melting temperature (primer specific) for $1 \mathrm{~min}, 72^{\circ} \mathrm{Cfor} 1 \mathrm{~min}$ and a final extension of $7 \mathrm{~min}$ at $72^{\circ} \mathrm{C}$. The PCR products were analysed on $3 \%$ agarose gels electrophoresis (Lonza LE agarose) stained with ethidium bromide run with a power pack set at $100 \mathrm{~V}$ for $2.5 \mathrm{~h}$ and visualized under Biored gel-doc system. The DNA polymorphism between the genotypes was observed based on length of amplified DNA fragment in terms of base pair compared with 100 bp DNA ladder.

Only clear and reproducible bands were selected for data analysis by scoring polymorphic bands qualitatively as present (1) or absent (0). The total numbers of bands, polymorphic bands, average number of bands per primer, polymorphism percentage, and Polymorphism information content (PIC) (Anderson et al., 1993) were calculated. These data were used to calculate the pair-wise genetic similarity index was calculated as per Jaccard's coefficient of similarity (Jaccard, 1908). This similarity matrix was subjected to the unweighted pair-group method for arithmetic averages analysis (UPGMA) to generate the dendrogram. These analyses were conducted using the software package, NTSYS-pc (Numerical Taxonomy System) Version 2.1 (Rohlf, 2000).

\section{Results and Discussion}

The analysis of variance revealed significant differences between the 33 genotypes for all the 11characters studied except the number of branches per plants. The aggregate effects of all the 11 characters were tested by the Wilk's criterion, indicating significant differences between the genotypes. Hence, the analysis of genetic divergence based on $\mathrm{D}^{2}$ values was considered relevant. Based on $\mathrm{D}^{2}$ values maximum diversity was observed between SaliTil_Darrang, collected from Darrang and NempoSoksu, collected from RARS (Diphu). Similarly, SaliTil_Koliabor and KolaTil_ Majuli were shown to be close relative due to the minimum $\mathrm{D}^{2}$ value between them. The constituents of different clusters with their source are presented in presented in Table 3.Multivariate analysis revealed that 33 genotypes were grouped into eight clusters with a single largest cluster of 23 genotypes (Cluster 1). Cluster 2 comprised of four genotypes and the rest six were solitary cluster indicating the impact of selection pressure in increasing the genetic diversity. Four lines collected from RARS, Diphu were placed in Cluster 2 because of high morphological similarity among the lines. Sesame lines from other regions were scattered across different clusters indicating substantial genetic variability among the other lines. Clustering of 
germplasm was not associated with the geographical distribution and mainly grouped due to their morphological differences and breeding history. Similar results have been reported by Solanki and Gupta (2001), Parameshwarappa et al., (2010), Abate and Mekbib (2015).

The intra- and inter-cluster $\mathrm{D}^{2}$ values among 8 clusters are presented in Table 4. The maximum inter cluster distance was observed between the cluster 6 (TKG 308) and cluster 8 (Punjab Til 1), indicating a wide divergence among the clusters. A high inter-cluster distance was also observed between cluster 6(TKG 308) and cluster 7 (Nga Na) followed by cluster 5 (AhuTil_Koliabor) and cluster 8 (Punjab Til 1).

The magnitude of heterosis largely depends on the degree of genetic diversity in the parental lines. Therefore, the genotypes from these diverse clusters could be used in a hybridization programme to obtain a broad spectrum of genetic variability in the segregating generations. The minimum intercluster distance was observed between clusters 3 (KolaTil_Tezpur) and 5 (AhuTil_Koliabor), suggesting that the genetic constitution of the genotypes in one cluster was in close proximity with the genotypes in the other cluster.

Hence, the genotypes from these clusters may not be useful in the hybridization programme. Combining inter-cluster distance and cluster mean value (Table 5), the genotypes Rama, Punjab Til 1, TKG 308 and Nga Na could be useful for exploitation of hybrid vigour and for getting good recombinant. The relative contribution of different characters towards genetic divergence (Table 6) revealed that yield per plant had the highest contribution followed by days to $50 \%$ flowering and 1000 grain weight. Therefore, these characters should be given importance for the selection of parents for further breeding programmes. These results are in agreement with that given by Velusami et al., (2008) for seed yield and 1000 seed weight; Parameshwarappa et al., (2010) for 1000 seed weight, number of capsules per plant and seed yield per plant, Bandila et al., (2011) for seeds per capsule and number of capsules per plant and Gangadhara et al., (2012) for yield per plant and 100 grain weight.

Out of 50 simple sequence repeat (SSR) primers tested initially, 27 polymorphic primers that gave clear banding pattern were used in the present study (Table 7). These 27 SSR primers produced 78 bands of which 49 were polymorphic $(62.82 \%)$. The level of polymorphism obtained in this study $(62.82 \%)$ was low compared with the previous study in which a high level of polymorphism was detected among Indian sesame genotypes were more than $73 \%$ (Kumar and Sharma, 2011). Each marker amplified 1 to 5 alleles with an average of 2.89 alleles per locus. The SSR markers in the present study showed a lower number of alleles than previous analysis of the diversity of sesame accessions conducted with SSR markers (Dixit et al., 2005; Gebremichaeland Parzies, 2011; Kumar and Sharma, 2011; Nweke et al., 2015; Pandey et al., 2015).

The polymorphism information content (PIC) value varied from 0.99 (SSR 46) to 0.01 (SSR 14) with a mean of 0.43 . The highest PIC value of 0.99 was observed for marker SSR46. It reflected a better discriminatory power of this primer to reveal a higher level of genetic diversity. In spite of having all the polymorphic loci PIC of SSR 14 was very low (0.01) indicating a less discriminatory power of this to distinguish genotypes under present study. Since PIC value closer to 1 is desirable four primers (SSR 46, SSR 10, SSR 33 and SSR 28) found to be suitable to discriminate the accessions. 
Table.1 Genotypes included in the present study

\begin{tabular}{|c|c|c|}
\hline SI. No. & Genotype Name & Source \\
\hline 1. & $\mathrm{Nga} \mathrm{Na}$ & Arunachal Pradesh, local \\
\hline 2. & KolaTil_Tezpur & Tezpur,local \\
\hline 3. & AhuTil_Kalibor & Kalibor,local \\
\hline 4. & NeiIong_Umium & Umium, local \\
\hline 5. & AhuTil_Lakhimpur & Lakhimpur, local \\
\hline 6. & SaliTil_Biswanath & Biswanath,local \\
\hline 7. & SaliTil_Kaliabor & Kaliabor,local \\
\hline 8. & PahariaTilNagaon & Nagaon, local \\
\hline 9. & AhuTil_Sibsagar & Sibsagar,local \\
\hline 10. & CUHY 57 & CalcuttaUniversity, mutant \\
\hline 11. & TKG 308 & HYV, Madhya Pradesh \\
\hline 12. & CUMS 17 & Calcutta University,mutant \\
\hline 13. & CUMS 04 & Calcutta University,mutant \\
\hline 14. & Uma & Calcutta University,mutant \\
\hline 15. & AhuTil_Puranigudam & Puranigudam, local \\
\hline 16. & V 12 & Calcutta University,local \\
\hline 17. & Rama & Calcutta University, selection from local 'Khosla' \\
\hline 18. & V 15 & Calcutta University, local \\
\hline 19. & SaliTil_Nagaon & Nagaon,local \\
\hline 20. & KolaTil_Nalbari & Nalbari,local \\
\hline 21. & SaliTil_Ghilamara & Ghilamara, local \\
\hline 22. & KolaTil_Majuli & Majuli, local \\
\hline 23. & SaliTil_Darrang & Darrang, local \\
\hline 24. & AST 1 & RARSDiphu,HYV local X ST1683 \\
\hline 25. & NempoThepo & RARSDiphu, local \\
\hline 26. & Punjab Til 1 & HYV \\
\hline 27. & NempoLongnicklu & RARSDiphu, local \\
\hline 28. & Nagaon Local & Nagaon, local \\
\hline 29. & NempoCharap & RARSDiphu, local \\
\hline 30. & NempoSoksu & RARSDiphu, local \\
\hline 31. & Kaliabor Local & Kaliabor, local \\
\hline 32. & Bahua Bheti & RARSDiphu, local \\
\hline 33. & NempoChindon & RARSDiphu, local \\
\hline
\end{tabular}


Table.2 SSR markers used in the present study

\begin{tabular}{|c|c|c|c|}
\hline & Primer sequence & Annealing temp. ${ }^{\circ} \mathrm{C}$ & Source \\
\hline SSR 1 & F: 5’-TCATATATAAAAGGAGCCCAAC-3’ R: 5-GTCATCGCTTCTCTCTTCTTC-3 & 55 & Nweke, 2015 \\
\hline SSR 3 & F: 5-CCCAACTCTTCGTCTATCTC-3 R: 5-TAGAGGTAATTGTGGGGGA-3 & 58 & Nweke, 2015 \\
\hline SSR 5 & F: 5-GCAGCAGTTCCGTTCTTG-3 R: 5-AGTGCTGAATTTAGTCTGCATAG-3 & 61 & Nweke, 2015 \\
\hline SSR 6 & F: 5-CCACTCAAAATTTTCACTAAGAA-3 R: 5-TCGTCTTCCTCTCTCCCC-3 & 61 & Nweke, 2015 \\
\hline SSR 7 & F: 5-GCAAACACATGCATCCCT-3 R: 5-GCCCTGATGATAAAGCCA-3 & 61 & Nweke, 2015 \\
\hline SSR 8 & F: 5-TTTCTTCCTCGTTGCTCG-3 R: 5-CCTAACCAACCACCCTCC-3 & 55 & Nweke, 2015 \\
\hline SSR 11 & F:5-AGAACAGGATCTTTCCTCCT-3 R:5-CTTAAGGTCGGAGAAGTCAAT-3 & 55 & Bhattacharyya et al., 2014 \\
\hline SSR 12 & F:5-CCACTTACATTGCACATACCT-3 R:5-CGTATTGCTGTTGGTCATATT -3 & 55 & Bhattacharyya et al., 2014 \\
\hline SSR 13 & F:5-GAATCGAACCTGATTGAACTA-3 R:5-GCCAGTGATAACCCATAAAGT-3 & 54 & Bhattacharyya et al., 2014 \\
\hline SSR 14 & F:5-GTAGACGAGCGAGAAAGAAA-3 R:5-CTTATCGAGCATCCAATGTT -3 & 55 & Bhattacharyya et al., 2014 \\
\hline SSR 15 & F:5-GGCATCAGTCCGTCTTTC -3 R:5- AAAACTAGAGACGAACAGC-3 & 56 & Bhattacharyya et al., 2014 \\
\hline SSR 16 & F:5-TTTTTACTTCCCGTTTCTTTC -3 R:5-GGTACTTGGTCTGGAATTCTT -3 & 55 & Bhattacharyya et al., 2014 \\
\hline SSR 21 & F:5-CTGAACAAGACAAGGGAATC-3 R:5-GACAGGGATTCAAGAGACAG-3 & 54 & Bhattacharyya et al., 2014 \\
\hline SSR 22 & F:5-ATTTGATACACCAACAGCAAC -3 R:5-TCCTTGCATCATTAGTGTGA -3 & 55 & Bhattacharyya et al., 2014 \\
\hline SSR 23 & F:5-ATCTACAAAAACATCCССТTC-3 R:5- ACATGAAACCTTTGAGTGATG-3 & 54 & Bhattacharyya et al., 2014 \\
\hline SSR 24 & F:5-CACAACAACCATCATCATGTA -3R:5-AGTGAAGTCGGAAGAGAAAGT & 55 & Bhattacharyya et al., 2014 \\
\hline SSR 25 & F:5-GCGTTTTTGTTATTGTTGAA -3 R:5-GTTTGCACTCTGAACAGTTTT-3 & 54 & Bhattacharyya et al., 2014 \\
\hline SSR 26 & F:5- GAGTAGTGCTCATCCTCACAG -3 R:5-GGACGGACAGTAACAGTAAGA-3 & 55 & Bhattacharyya et al., 2014 \\
\hline SSR 27 & F:5-CCGCTCTTACTGTTACTGTCC-3 R:5-TGACAAGAGAAGGAGAAGTGA & 56 & Bhattacharyya et al., 2014 \\
\hline SSR 28 & F:5-СТСССТCTТССТСТTCTTCTT-3 R:5- CGAGCCATTCATAGATACAAC-3 & 55 & Bhattacharyya et al., 2014 \\
\hline SSR 29 & F:5-TTTTTGTCACACTCCCTTTC -3 R:5-GACATAGAGAAAGGTCTCTG-3 & 55 & Bhattacharyya et al., 2014 \\
\hline SSR 30 & F:5-AATCAGTGAATTAGCAGCATC-3 R:5-GTTGAGAGTGTGCGAAGAAT -3 & 54 & Bhattacharyya et al., 2014 \\
\hline SSR 31 & F:5-CAGATCTGTTCCTATGGGTTT-3 R:5- ATCTCCTTAATTAACCCAGCA-3 & 55 & Bhattacharyya et al., 2014 \\
\hline SSR 32 & F:5-TTTTCTCTCTCTCTCTCTCTCTC -3 R:5- CCCTCTGTATGTCTTCAGTTG -3 & 53 & Bhattacharyya et al., 2014 \\
\hline SSR 33 & F:5-ACAATCGTAGTCCTTTCTTGA-3 R:5- GCAAAGGTTGTTGTTGTCTC-3 & 54 & Bhattacharyya et al., 2014 \\
\hline
\end{tabular}




\begin{tabular}{|l|}
\hline SSR 34 \\
\hline SSR 35 \\
\hline SSR 36 \\
\hline SSR 37 \\
\hline SSR 38 \\
\hline SSR 39 \\
\hline SSR 40 \\
\hline SSR 41 \\
\hline SSR 42 \\
\hline SSR 43 \\
\hline SSR 44 \\
\hline SSR 45 \\
\hline SSR 46 \\
\hline SSR 47 \\
\hline SSR 48 \\
\hline SSR 49 \\
\hline SSR 50 \\
\hline
\end{tabular}

F:5-CTAAGAAAACCGTAGCTCCA-3 R:5-GTAGGTTCAGATTTTGCCTCT -3 F:5-CCTCTCCACTGCTACCTACTA -3 R:5-TCAACAGGAAAAGAGAGAGAA-3 F:5-CTACACTGTCAACAGCAACAA -3 R:5- AACCTCAACGGTAGGATTTC F:5-GAACCCAGTCATTCTTTATCC-3 R:5- TTTAAAGGGTGGTTATGTGTG-3 F:5-AGTTCAAAGAATCCCTCGAC-3 R:5- GCGAGTCGTCACTCTCAT -3 F:5-TTCCTTCTCACACATTCACC -3 R:5- GATCTGATTCACCTCCTTCTG -3 F:5-CCAACTTAAGACCCAAGAAC-3 R:5- GTCATCAATGGAAGAACTCTG-3 F:5-AGAAGATCAAGGACAAGATCC-3 R:5- GATTCAAGCACACCTGAATTA -3 F:5-ATCCCACCATACTTTCTTCTC-3 R:5-CAATTGGGAGTAAATGACAAC-3 F:5-ACCTTTGGAATGAGAGGTAAC-3 R:5-GCAGCTGATTGTAAGAGAAGA -3 F:5-GAAGAAGAGGAGGAAGAAGAA-3 R:5-CCTTGTCTAGTCTTGAGTTGG-3 F:5'-GAAGGTCTGCGAGTACTTTG-3' R:5;-CCTCCAAGGAGATACAAATTC -3' F:5'-GCAAACACATGCATCCCT-3' R:5'-GCCCTGATGATAAAGCCA-3' F:5-'GCAGCAGTTCCGTTCTTG-3' R:5'-AGTGCTGAATTTAGTCTGCATAG-3' F:5'-GCTGAGGAGTCTTGAAGCAGA-3' R:5'-CAAAATCCCCCAACTCGATA-3' F:5'-AAACCCGCTAAGGGACTCAT-3' R:5'-CATGGCTTCTGGCTTTCTTC-3' F:5'-TGCAGGAATGAACTCAAGGA-3' R:5'-ACCTTATTCCCAGCCCACTT-3'

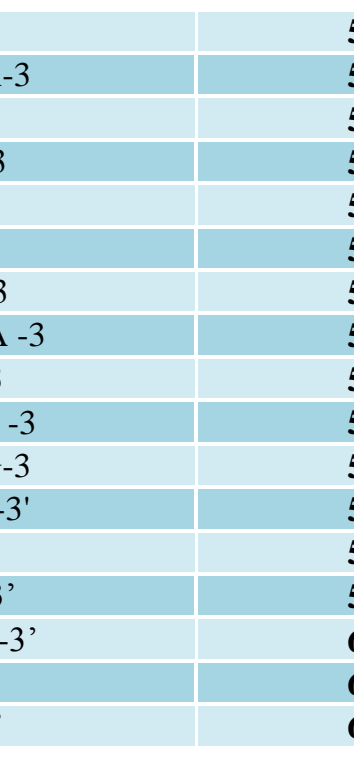

\begin{tabular}{|c|c|}
\hline 54 & Bhattacharyya et al., 2014 \\
\hline 53 & Bhattacharyya et al., 2014 \\
\hline 54 & Bhattacharyya et al., 2014 \\
\hline 55 & Bhattacharyya et al., 2014 \\
\hline 55 & Bhattacharyya et al., 2014 \\
\hline 56 & Bhattacharyya et al., 2014 \\
\hline 53 & Bhattacharyya et al., 2014 \\
\hline 54 & Bhattacharyya et al., 2014 \\
\hline 54 & Bhattacharyya et al., 2014 \\
\hline 54 & Bhattacharyya et al., 2014 \\
\hline 54 & Bhattacharyya et al., 2014 \\
\hline 55 & Bhattacharyya et al., 2014 \\
\hline 58 & Pandey et al., 2015 \\
\hline 52 & Pandey et al., 2015 \\
\hline 60 & Pandey et al., 2015 \\
\hline 60 & Pandey et al., 2015 \\
\hline 60 & Pandey et al., 2015 \\
\hline
\end{tabular}

Table.3 Clustering pattern among sesame genotypes in $\mathrm{D}^{2}$ analysis using morphological traits

\begin{tabular}{|c|c|c|}
\hline Cluster no. & Number of genotypes & Name of the genotypes \\
\hline 1 & 23 & $\begin{array}{l}\text { PahariaTil_Nagaon, CUHY 57, KolaTil_Majuli, NeiIong_Umium, Uma, AST 1, SaliTil_Kaliabor, AhuTil_ } \\
\text { Sivsagar, KolaTil_Nalbari, CUMS 17, V12, Bahuabheti, CUMS 04, Koliabor Local, SaliTil_Ghilamara, } \\
\text { SaliTil_Nagaon, AhuTil_Lakhimpur, SaliTil_Darrang, SaliTil_Biswanath, Nagaon Local, NempoChindon, V } \\
\text { 15, AhuTil_Puranigudam }\end{array}$ \\
\hline 2 & 4 & NempoLongnicklu, NempoSoksu, NempoThepo, NempoCharap \\
\hline 3 & 1 & KolaTil_Tezpur \\
\hline 4 & 1 & Rama \\
\hline 5 & 1 & AhuTil_Koliabor \\
\hline 6 & 1 & TKG 308 \\
\hline 7 & 1 & $\mathrm{Nga} \mathrm{Na}$ \\
\hline 8 & 1 & Punjab Til 1 \\
\hline
\end{tabular}


Table.4 Intra diagonal and inter cluster $\mathrm{D}^{2}$ values for different characters in sesame genotypes

\begin{tabular}{|c|c|c|c|c|c|c|c|c|}
\hline & Cluster 1 & Cluster 2 & Cluster 3 & Cluster 4 & Cluster 5 & Cluster 6 & Cluster 7 & Cluster \& \\
\hline Cluster 1 & 9.27 & 22.18 & 17.63 & 16.22 & 21.26 & 20.36 & 37.02 & 45.49 \\
\hline Cluster 2 & & 3.62 & 27.24 & 26.40 & 38.86 & 59.11 & 34.54 & 20.59 \\
\hline Cluster 3 & & & 0.00 & 32.60 & 8.28 & 29.94 & 18.61 & 56.54 \\
\hline Cluster 4 & & & & 0.00 & 27.89 & 36.36 & 34.99 & 47.51 \\
\hline Cluster $\mathbf{5}$ & & & & & 0.00 & 32.97 & 10.65 & 67.27 \\
\hline Cluster 6 & & & & & & 0.00 & 69.92 & 79.59 \\
\hline Cluster 7 & & & & & & & 0.00 & 61.58 \\
\hline Cluster 8 & & & & & & & & 0.00 \\
\hline
\end{tabular}

Table.5 Cluster mean for different characters in sesame genotypes

\begin{tabular}{|c|c|c|c|c|c|c|c|c|c|c|c|}
\hline & $\begin{array}{c}\text { Height of } \\
1^{\text {st capsule bearing }} \\
\text { node } \mathrm{cm}\end{array}$ & $\begin{array}{l}\text { Plant } \\
\text { height } \\
\text { cm }\end{array}$ & $\begin{array}{l}\text { Capsules/ } \\
\text { plant no. }\end{array}$ & $\begin{array}{l}\text { Branches/ } \\
\text { plant no. }\end{array}$ & $\begin{array}{l}\text { Capsule } \\
\text { length } \mathrm{cm}\end{array}$ & $\begin{array}{c}\text { Capsule } \\
\text { width } \mathrm{cm}\end{array}$ & $\begin{array}{c}\text { Seeds/ capsule } \\
\text { no. }\end{array}$ & $\begin{array}{c}1000 \\
\text { grain wt. } \\
\mathrm{g}\end{array}$ & $\begin{array}{l}\text { Days to } 50 \% \\
\text { flowering }\end{array}$ & $\begin{array}{l}\text { Days to } \\
\text { maturity }\end{array}$ & $\begin{array}{l}\text { Yield/ } \\
\text { plant g }\end{array}$ \\
\hline Cluster 1 & 30.48 & 67.70 & 25.94 & 2.55 & 2.09 & 0.71 & 43.56 & 2.83 & 36.90 & 94.26 & 9.50 \\
\hline Cluster 2 & 39.10 & 71.01 & 26.77 & 2.95 & 2.22 & 0.74 & 37.48 & 2.09 & $44.33 * *$ & 97.00 & 9.06 \\
\hline Cluster 3 & 37.73 & $85.87 * *$ & 32.20 & 2.40 & $2.06^{*}$ & 0.75 & $53.83 * *$ & 2.74 & 35.33 & 94.33 & 6.43 \\
\hline Cluster 4 & 39.27 & 70.00 & 72.40 *** & $3.83 * *$ & 2.33 & $0.65^{*}$ & 46.80 & 2.92 & 40.33 & 93.33 & $9.63 * *$ \\
\hline Cluster 5 & $23.07 *$ & $55.20^{*}$ & 18.27 & 2.27 & 2.17 & 0.68 & 51.73 & 2.83 & 35.67 & 99.33 & 6.07 \\
\hline Cluster 6 & 30.47 & 62.33 & $15.07 *$ & $1.63 *$ & 2.15 & $0.65^{*}$ & 46.93 & $3.40 * *$ & $29.33^{*}$ & $83.67^{*}$ & 9.30 \\
\hline Cluster 7 & 32.80 & 65.63 & 39.33 & 3.75 & 2.13 & 0.69 & $36.90 *$ & 2.60 & 39.33 & $104.33^{* * *}$ & $5.10^{*}$ \\
\hline Cluster 8 & $54.24 * *$ & 57.80 & 15.08 & 2.93 & $2.79 * *$ & $0.87 * *$ & 46.60 & $2.04 *$ & 42.00 & 102.00 & 9.53 \\
\hline
\end{tabular}

Table.6 Contributions of different characters towards clustering in sesame genotypes

\begin{tabular}{|c|}
\hline Source \\
\hline Height of $1^{\text {st }}$ capsule bearing nodecm \\
\hline Plant height cm \\
\hline Capsules/ plant no. \\
\hline Branches/ plantno. \\
\hline Capsule length cm \\
\hline Capsule width cm \\
\hline Seeds/ capsuleno. \\
\hline 1000 grain wt.g \\
\hline Days to 50\% flowering \\
\hline Days to maturity \\
\hline Yield/ plantg
\end{tabular}

\begin{tabular}{|c|c|}
\hline Times ranked $\mathbf{1}^{\text {st }}$ & Contribution \% $^{\text {Tim }}$ \\
\hline 3 & $0.57 \%$ \\
\hline 4 & $0.76 \%$ \\
\hline 34 & $6.44 \%$ \\
\hline 2 & $0.38 \%$ \\
\hline 34 & $6.44 \%$ \\
\hline 11 & $2.08 \%$ \\
\hline 37 & $7.01 \%$ \\
\hline 104 & $19.70 \%$ \\
\hline 108 & $20.45 \%$ \\
\hline 148 & $8.14 \%$ \\
\hline
\end{tabular}


Table.7 Marker polymorphism analysis in sesame genotypes using SSR marker

\begin{tabular}{|c|c|c|c|c|}
\hline Marker name & Total band amplified & Number of polymorphic bands & $\%$ polymorphism & PIC \\
\hline SSR 1 & 3 & 1 & 33.33 & 0.43 \\
\hline SSR 2 & 2 & 2 & 100.00 & 0.27 \\
\hline SSR 5 & 2 & 1 & 50.00 & 0.56 \\
\hline SSR 6 & 4 & 4 & 100.00 & 0.24 \\
\hline SSR 7 & 3 & 2 & 66.67 & 0.17 \\
\hline SSR 8 & 3 & 3 & 100.00 & 0.68 \\
\hline SSR 9 & 2 & 1 & 50.00 & 0.47 \\
\hline SSR 10 & 3 & 3 & 100.00 & 0.95 \\
\hline SSR 11 & 3 & 2 & 66.67 & 0.09 \\
\hline SSR 12 & 3 & 1 & 33.33 & 0.51 \\
\hline SSR 14 & 4 & 4 & 100.00 & 0.01 \\
\hline SSR 17 & 2 & 1 & 50.00 & 0.23 \\
\hline SSR 19 & 4 & 1 & 25.00 & 0.74 \\
\hline SSR 22 & 3 & 2 & 66.67 & 0.16 \\
\hline SSR 28 & 3 & 1 & 33.33 & 0.85 \\
\hline SSR 29 & 3 & 2 & 66.67 & 0.26 \\
\hline SSR 30 & 5 & 2 & 40.00 & 0.33 \\
\hline SSR 32 & 2 & 1 & 50.00 & 0.47 \\
\hline SSR 33 & 2 & 1 & 50.00 & 0.87 \\
\hline SSR 34 & 4 & 3 & 75.00 & 0.29 \\
\hline SSR 36 & 2 & 2 & 100.00 & 0.23 \\
\hline SSR 44 & 3 & 1 & 33.33 & 0.43 \\
\hline SSR 46 & 3 & 1 & 33.33 & 0.99 \\
\hline SSR 47 & 3 & 2 & 66.67 & 0.34 \\
\hline SSR 48 & 3 & 3 & 100.00 & 0.16 \\
\hline SSR 49 & 2 & 1 & 50.00 & 0.51 \\
\hline SSR 50 & 2 & 1 & 50.00 & 0.33 \\
\hline Average & 2.89 & 1.81 & 62.82 & 0.43 \\
\hline
\end{tabular}


Fig.1 Dendrogram Showing Genetic Relationship among the Sesame Genotypes

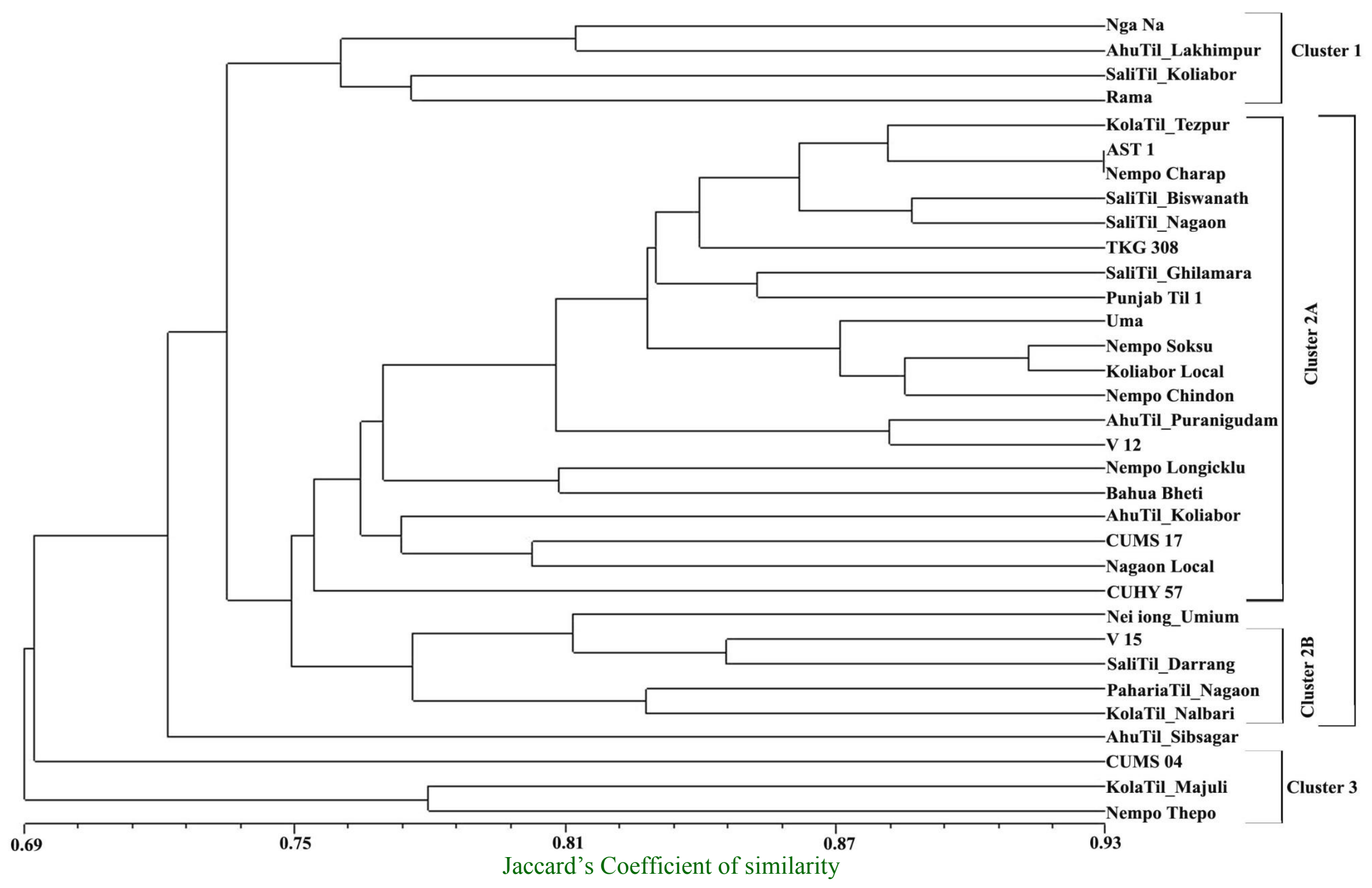


Diversity analysis with the use of molecular markers determines the degree of relatedness and help in an accurate grouping of the genotypes to identify parents for exploitation of heterosis and to detect the duplication. Jaccard's similarity coefficients ranged from 0.931 to 0.591 with an average of 0.754 .

The maximum similarity between NempoCharap and AST1 (0.931) indicated close correspondence in their DNA based on present marker analysis. The minimum similarity was exhibited between AST 1 and KolaTil_Majuli (0.591) indicated diverse nature of those genotypes. Such diverse nature is obvious as AST 1 is an HYV developed by AAU, whereas KolaTil_Majuli is a local genotype collected from largest river island Majuli. Genetic relationships based on UPGMA cluster analysis identified three major clusters (Fig: 1). The cluster analysis revealed that KolaTil_Majuli and NempoThepo (Cluster 3) showed maximum divergence from the rest of the genotypes followed by CUMS 04 and AhuTil_Sibsagar. For the rest of the genotypes, two clusters were observed. Cluster 1 comprised of four genotypes and cluster 2 included 25 genotypes divided into two sub-clusters at a similarity coefficient of 0.75 .

High polymorphic and genetic diversity will be useful for the breeder to incorporate them in a breeding programme. The present study indicated sufficient genetic diversity at DNA level and no congruence between clustering pattern done by $\mathrm{D}^{2}$ and that based on DNA was recorded. Most of the materials use in the present study were from different location of North East India which form different groups at morphological and DNA level. Such clustering pattern indicated that there is greater diversity among the sesame genotype grown in the location and these germplasms will be the source of valuable gene system for the sesame breeder.

\section{References}

Abate, M., and Mekbib, F. 2015.Study on genetic divergence in low-altitude sesame Sesamum indicum L.) Germplasm of Ethiopia based on agro-morphological traits. Sciences. 2, 78-90.

Anderson, J. A., Churchill, G.A., Atrique, J.E., Tanksley, S.D. and Sorrels, M.E. 1993. Optimizing parental selection of genetic linkage maps.Genome.36, 181-186.

Anonymous, 2017. Nmoop.gov.in/Presentations/sesame_2830-2017.pptx as visited on 9 January 2016.

Ashri, A., 1998. Sesame breeding. Plant Breed. Rev.16, 179-228.

Bandila, S., Ghanta, A., Natarajan, S. and Subramoniam, S. 2011. Determination of genetic variation in Indian sesame Sesamum indicum genotypes for agromorphological traits. J Res Agril Sci.7, 88-99.

Bisht, I.S., Mahajan, R.K., Loknathan, T.R. and Agrawal, R.C. 1998. Diversity in Indian sesame collection and stratification of germplasm accessions in different diversity groups. Gen Res Crop Evol. 45, 325-335.

Dixit, A., Jin, M. H., Chung, J.W., Yu, J.W., Chung, H.K., Ma, K.H. and Cho, E.G. 2005. Development of polymorphic microsatellite markers in sesame Sesamum indicum L. MolEcol Res. 5, 736-738.

Farooq, M.A., Ali, B., Gill, R.A., Islam, F., Cui, P. and Zhou, W. 2016. Breeding Oil Crops for Sustainable Production. In: Gupta SK ed Heavy Metal Tolerance, Elsevier Inc., pp. 19-31.

Gangadhara, K., Prakash, J.C., Rajesh, A.M., Gireesh, C., Somappa, J. and Yathish, K.R. 2012. Correlation and path coefficient analysis in sesame Sesamum indicum L. BIOINFOLET-A Quart. J Life Sci. 9, 303-310.

Gebremichael, D.E., and Parzies, H.K. 2011. Genetic variability among landraces of 
sesame in Ethiopia. African Crop Sci J. 19, 1-13.

Jaccard, P., 1908. Nouvelles researches sur la distribution florale. Bull Soc Vaud Sci Nat. 44, 223-270.

Kumar, V., Sharma, S.N. 2011. Comparative potential of phenotypic, ISSR and SSR markers for characterization of sesame Sesamum indicum L. varieties from India. J Crop Sci. Biotechnol. 14, 163-171.

Murray, M.G., Thompson, W.F. 1980. Rapid isolation of high molecular weight plant DNA. Nucleic Acids Res. 8, 4321-4326.

Nweke, F.N., 2015. Genetic diversity of Nigerian sesame cultivars Sesamum indicum $\mathrm{L}$ based on simple sequence repeat SSR markers and its relationship with phytochemicals. Intern. J CurrMicrobiol App Sci.4, 898-908.

Pandey, S.K., Das, A., Rai, P. and Dasgupta, T. 2015. Morphological and genetic diversity assessment of sesame Sesamum indicum L. accessions differing in origin. PhysiolMolBiol Plants. 21, 519529.

Parameshwarappa, S.G., Palakshappa, M.G., Salimath, P.M. and Parameshwarappa, K.G. 2010.Analysis of genetic divergence in sesame, Sesamum indicum L. Karnataka J Agric Sci. 23, 227-230.

Rao, C.R., 1952. Advanced Statistical Methods in Biometrical Research.John Wiley and Sons, New York, pp.357-369.

Rohlf, F.J., 2000.NTSYSpc: Numerical taxonomy and multivariate system. Version 2.1 Exeter Software. Applied Biostatics Inc., New York.

Sehr, E.M., Okello-Anyanga, W., Hasel-Hohl, K., Burg, A., Gaubitzer, S., Rubaihayo, P.R. and Fluch, S.J. 2016. Assessment of genetic diversity amongst Ugandan sesame Sesamum indicum L. landraces based on agro-morphological traits and genetic markers. Crop Sci. Biotechnol. 19, 117-129.

Sharma, E., Shah, T.I. and Khan, F., 2014. A review enlightening genetic divergence in Sesamum indicum based on morphological and molecular studies. Intern J Agric Crop Sci. 7, 1-9.

Sharma, S.N., Kumar, V. and Mathur, S. 2009. Comparative analysis of RAPD and ISSR markers for characterization of sesame Sesamum indicum L. genotypes. J Plant Biochem Biotechnol. 18, 37-43.

Solanki, Z.S., and Gupta, D. 2001. Variability and genetic divergence studies in sesame Sesamum indicum L. Sesame Safflower Newsl.16, 28-31.

Velusami, P.A., Thirugnanakumar, S., Balamurugan, R., Praveen S. K. C. and Eswaran, R. 2008. D ${ }^{2}$ statistics in sesame Sesamum indicum L. over environments. Ad Plant Sci. 21, 649-650.

Wu, K., Yang, M., Liu, H., Tao, Y., Mei, J. and Zhao, Y. 2014. Genetic analysis and molecular characterization of Chinese sesame Sesamum indicum L. cultivars using Insertion-Deletion InDel and Simple Sequence Repeat SSR markers. BMC Genetics.15, 35-49.

Yepuri V, Surapaneni M, Kola VSR, Vemireddy LR, Jyothi B, Dineshkumar V, Siddiq EA 2013 Assessment of genetic diversity in sesame Sesamum indicum L. genotypes, using EST-derived SSR markers. J Crop SciBiotechnol 16: 93103.

\section{How to cite this article:}

Labhya Rani Gogoi, Sushil Kumar Singh and Sarma R. N. 2018. Assessment of Genetic Diversity in Indigenous Sesame Genotypes. Int.J.Curr.Microbiol.App.Sci. 7(06): 1509-1520. doi: https://doi.org/10.20546/ijcmas.2018.706.179 